\title{
A study of the depth perception of monocular hooded rats on the visual cliff'
}

\author{
Samuel Tryehin, Jr. and Riehard D. Walk \\ GEORGE WASHINGTON UNIVERSITY
}

\begin{abstract}
The visual cliff was used to test the depth perception of monocular hooded rats when both texture density and depth were varied, when depth was varied but texture density held constant, and when Ss were kept in the dark after the eye was removed before being tested on the equal density condition. An additional group was tested for preference for "coarse", over "fine" texture densities. Under all conditions monocular Ss behaved like binocular controls, showing the adequacy of monocular cues for depth perception.
\end{abstract}

\section{Problem}

Many investigations of depth perception or depthrelated behavior have found normal behavior with only one eye (Spalding, 1873; Canella, 1936), but only recently have studies been performed where the visual stimulus is adequately controlled. The present study uses the visual cliff (Walk \& Gibson, 1961), an apparatus that controls for nonvisual cues.

Schiffman and Walk (1963) and Shinkman (1963), with the monocular chick, and Walk and Dodge (1962), with a monocular human infant, have observed depth discrimination on the visual cliff. The present investigation extends the study of monocular depth perception to the hooded rat. Four experiments are reported: Experiment I varied depth and texture density. Experiment II varied depth but equated for texture density. In Experiment III, Ss were kept in the dark after monocularization, then tested on the equal density condition, to control for any learning during the 24-hr. recovery period. Experiment IV gave the S a choice of the two textures used in Experiments II and III, one "coarse" and the other "fine."

\section{Method}

The apparatus was a copy of visual cliff model II described in Walk and Gibson (1961). It was a hollow rectangular box $32 \times 20 \times 12$ in with a floor of glass. A center board ( $18 \times 31 / 2 \times 4$ in) bisected the glass floor into two equal segments about $13 \times 18$ in. The pattern under the "shallow" side was placed on a piece of masonite that slid into slots directly under the glass. The pattern on the "deep" side was 10 in below the glass.

The texture for the first experiment was $3 / 4$ in red and white checked oilcloth on both shallow and deep sides. The second and third experiments used $1 / 4$ in red and white checks on the shallow side and $3 / 4$ in checks on the deep side to equate for texture density. The fourth experiment used 1/4 in checks on one side of the center board and $3 / 4$ in checks on the other, both patterns directly under the glass.

Half of the animals had the right eye removed surgically under Nembutal and half had the left eye removed.

Table 1. Behavior of Monocular and Binocular Hooded Rats in the Four Experiments

$$
\begin{aligned}
& \text { Number Descending to: } \\
& \text { N Shallow Side } \quad \text { Deep Side } \quad \text { No Descent } \quad \text { z (shallow vs. deep) }
\end{aligned}
$$

Exp. I: Depth and Density Varied

5

5

7

Monocular Ss $\quad 42$

Binocular Ss $\quad 45$

24

30

Exp. II: Depth Varied, Density Equal

Monocular Ss $\quad 30 \quad 20$

Binocular Ss

30
12

10

5

4

14

$2.00 *$

Monocular Ss
18

16

15
30
30

Monocular Ss
Binocular Ss

$* \mathrm{P}<.05$

$* * \mathrm{P}<.01$ means descent to finer pattern. 
Animals were allowed 24-hr. recovery in the animal colony after the operation except for Ss in Experiment III where recovery was for $24 \mathrm{hr}$. in a light-proof room.

Ss were hooded Long-Evans rats, approximately 90 days old, 141 monocular and 105 binocular.

Animals were placed individually on the center board and observed for side of descent. If $\mathrm{S}$ did not descend from the center board in $3 \mathrm{~min}$. it was removed and "no descent" recorded. To control for extra cues, Ss were placed systematically at each end of the center board and shallow and deep sides were changed every 6 Ss. Monocular and binocular Ss were tested alternately. The glass floor was cleaned after each $\mathrm{S}$ was tested.

\section{Results}

The results are shown in Table 1 . Under all conditions there is no significant difference between monocular Ss and their binocular controls. Monocular Ss descended significantly more often to the shallow side when both depth and texture density were varied (Experiment I), when the two patterns projected equal densities to the S's eye (Experiment II), and the Ss were kept in the dark until tested on the equal density condition (Experiment III). In Experiment IV, monocular Ss significantly descended to the coarser or larger pattern. While binocular controls for these Ss did not significantly choose the larger textured pattern (only 60\% chose it), the two groups did not differ significantly. Monocular Ss, with $76 \%$ choice of the large pattern, behaved like the binocular Ss in Walk and Gibson (1961) where 84\% descended to the larger pattern.

Thus, this experiment demonstrates depth perception in the monocular hooded rat that is indistinguishable from binocular controls when equal texture densities are projected from each side of the apparatus, and when Ss are kept in the dark between enucleation and testing to control for possible learning during the recovery period.

\section{Referenees}

CANELLA, M. F. Les problemes du chiasma et de la vision binoculaire. Quelques recherches sur la vision monoculaire. J. de Psychol. norm. et path., 1936, 33, 696-711.

SCHIFFMAN, H. R., \& WALK, R. D. Behavior on the visual cliff of monocular as compared to binocular chicks. J. comp. physiol. Psychol., 1963, 56, 1064-1068.

SHINKMAN, P. G. Visual depth discrimination in dayold chicks. J. comp. physiol. Psychol., 1963, 56, 410-414.

SPALDING, D. A. Instinct with original observations on young animals. Macmillan's magazine, 1873, 27, 282-293.

WALK, R. D., \& DODGE, SUE H. Visual depth perception of a 10-month-old monocular human infant. Science, 1962, 137, 529-530.

WALK, R. D., \& GIBSON, ELEANOR J. A comparative and analytical study of visual depth perception.Psychol. Monogr., 1961, 75, No. 15 (Whole No. 519).

\section{Note}

1. This study is based on a thesis submitted by the first author under the direction of the second author to George Washington University in partial fulfillment of the degree of Master of Arts, February 1962. The research was supported in part by a grant from the National Science Foundation. 